\title{
EFECTO DE LAS MICORRIZAS ARBUSCULARES EN EL CRECIMIENTO, FOTOSÍNTESIS Y ANATOMÍA FOLIAR DE PLANTAS JÓVENES DE AGAVE TEQUILANA
}

\author{
Eulogio Pimienta-Barrios ${ }^{1}$, Julia Zañudo-HernándeZ ${ }^{1}$ Y \\ EDUARDO LÓPEZ-AlCOCER ${ }^{2}$
}

\author{
${ }^{1}$ Universidad de Guadalajara, Centro Universitario de Ciencias Biológicas y \\ Agropecuarias, Departamento de Ecología, km 15.5 carretera a Nogales, \\ 45110 Las Agujas, Zapopan, Jalisco, México. \\ epimient@cucba.udg.mx \\ ${ }^{2}$ Universidad de Guadalajara, Centro Universitario de Ciencias Biológicas y \\ Agropecuarias, Departamento de Ciencias Ambientales, km 15.5 carretera a \\ Nogales, 45110 Las Agujas, Zapopan, Jalisco, México.
}

\section{RESUMEN}

Se evaluó el efecto de la simbiosis de hongos micorrícicos vesículo arbusculares (MVA) en el crecimiento, la fotosíntesis estacional y la anatomía foliar en plantas jóvenes de Agave tequilana. Éstas se establecieron en macetas y fueron inoculadas con una de dos cepas de hongos MVA: Glomus fasciculatum (Gf) o Glomus intraradices (Gi), para su comparación con testigos sin inoculación. Para la evaluación de estos tratamientos se usó un diseño experimental completamente al azar, con seis repeticiones, en un total de 18 unidades experimentales. Las variables fisiológicas y morfológicas evaluadas fueron: tasa de fotosíntesis, número de hojas jóvenes, longitud, ancho y grosor de hojas maduras, y porcentaje de colonización de raíces por hongos MVA. La inoculación incrementó la fotosíntesis, siendo ésta mayor en individuos tratados con la cepa Gi que con la Gf y las plantas testigo, lo cual se relacionó con un aumento en el grosor del mesófilo, que fue más notable en el clorénquima. Sin embargo, las micorrizas no afectaron las variables relacionadas con el crecimiento, la longitud y el ancho de las hojas.

Palabras clave: Agave tequilana, anatomía foliar, crecimiento, fotosíntesis estacional, Metabolismo Ácido de las Crasuláceas, simbiosis micorrícica. 


\begin{abstract}
The effect of vesicular arbuscular micorrhizal symbiosis (VAM) in growth, seasonal photosynthesis, and foliar anatomy was evaluated on young plants of Agave tequilana. These were established in pots and inoculated with one of two strains of VAM fungi: Glomus fasciculatum (Gf) or Glomus intraradices (Gi), and compared with control plants without inoculation. To evaluate these treatments a completely randomized experimental design was used with six replications and 18 experimental units. The physiological and morphological variables evaluated were: photosynthetic rate, number of young leaves, length and thickness of mature leaves, and percentage of root colonization by VAM fungi. The inoculation increased photosynthetic rate, which was highest in plants inoculated with the Gi strain than both those inoculated with the Gf and the control plants, and it was related with an increase in mesophyll thickness that was most noticeable in the chlorenchyma tissue. However, the variables related to growth, length and width of leaves were unaffected.
\end{abstract}

Key words: Agave tequilana, Crassulacean Acid Metabolism, growth, leaf anatomy, mycorrhizal symbiosis, seasonal photosynthesis.

\title{
INTRODUCCIÓN
}

La historia evolutiva de las plantas vasculares indica una estrecha asociación simbiótica con microorganismos del suelo (Morton, 2000; Trappe, 2005; Wang y Quiu, 2006). Una de las relaciones más ampliamente estudiadas es la simbiosis micorrícica vesículo arbuscular (MVA), que es una vinculación entre hongos biotróficos del orden Glomales (clase Zygomycetes) y el sistema radical de los vegetales (Morton y Benny, 1990). Las estructuras comunes de los hongos MVA en la raíz de las plantas que colonizan son: vesícula, arbúsculo, hifa y micelio externo (Smith y Read, 1997). Aunque cada uno de estos elementos desempeña un papel importante en la simbiosis micorrícica (Ferrera-Cerrato y González-Chávez, 1998), el arbúsculo se considera como la estructura más importante desde el punto de vista fisiológico, ya que en ésta se lleva a cabo el intercambio nutricional entre el hongo y el hospedero (Orcutt y Nilsen, 2000).

La mutua dependencia del organismo hospedante y del huésped (hongos MVA) consiste en que el primero representa una fuente directa de carbono y nitrógeno, elementos indispensables para el desarrollo del segundo; por su parte, el huésped forma una red fúngica laxa con desarrollo intra e intercelular en la corteza 
radical de la planta, que se extiende hacia su entorno. Mediante este retículo las raíces absorben agua y minerales (sobre todo fósforo) en regiones del suelo que están fuera de los límites naturales de exploración radical y que son transportados a los diferentes órganos del vegetal. Tal proceso favorece su desarrollo, pues se incrementa la provisión de estos recursos, lo que se refleja en una mayor eficiencia fotosintética y una menor incidencia de organismos patógenos (Safir, 1990; Kyde y Gould, 2000). Además, los hongos MVA modifican las relaciones hídricas de las plantas mediante diferentes mecanismos, los cuales incluyen una ampliación en el área de superficie de raíces micorrícicas, regulación estomática y una menor resistencia en el transporte del agua y los solutos, mejorando su movilidad en el hospedero. Todo esto se refleja en un incremento en la conductividad hidráulica (Ruiz-Lozano y Azcón, 1995; Orcutt y Nilsen, 2000).

Los estudios sobre los efectos de la simbiosis micorrícica en la fisiología de plantas con metabolismo ácido de las crasuláceas (CAM, siglas en inglés), como es el caso de Agave tequilana, son escasos en comparación con las del tipo $\mathrm{C}_{3}$ (Cui y Nobel, 1992; Pimienta-Barrios et al., 2003). El presente trabajo se realizó después de que uno de los autores (Pimienta-Barrios) llevara a cabo observaciones que mostraron que la especie mencionada incrementó su desarrollo en respuesta a la inoculación con hongos micorrícicos; sin embargo, no se especificaron algunos de los posibles efectos de tal reacción. Por lo tanto, en esta investigación se evaluó el efecto de dos cepas fúngicas MVA en el crecimiento, la anatomía foliar y la fotosíntesis en A. tequilana, con el propósito de determinar la existencia de una correlación entre ellos.

\section{MÉTODOS}

Descripción del sitio de estudio

Este estudio se efectuó de septiembre de 1999 a noviembre de 2000 en el campo experimental del Departamento de Ecología de la Universidad de Guadalajara en Zapopan, Jalisco, México, ubicado en $20^{\circ} 5^{\prime} \mathrm{N}, 103^{\circ} 32^{\prime} \mathrm{O}$, a $1420 \mathrm{~m}$ de altitud. De acuerdo con la clasificación de Köppen modificada por García (1981), el clima es del tipo $\mathrm{Aw}_{0}(\mathrm{w})(\mathrm{e}) \mathrm{g}$, que se caracteriza por ser subhúmedo, con $930 \mathrm{~mm}$ de precipitación pluvial en promedio anual, de la cual la mayor parte (alrededor de $90 \%$ ) se presenta en el verano (junio-octubre), con lluvias escasas en invierno. La temperatura promedio anual es de $21{ }^{\circ} \mathrm{C}$, con una oscilación en el año entre 7 y $28^{\circ} \mathrm{C}$. 
Los datos de precipitación y de temperaturas máximas y mínimas durante el experimento se obtuvieron de la Quinta Base Aérea Militar Mexicana, que se ubica a $10 \mathrm{~km}$ del sitio de estudio, y los datos climáticos históricos de 1990 al 2006 los proporcionó la Comisión Nacional del Agua (CONAGUA).

Establecimiento del experimento

El 12 de febrero de 1999 se trasplantaron hijuelos de A. tequilana de dos años de edad en 18 recipientes de plástico (201 de capacidad), los cuales estaban llenos hasta la mitad con suelo de textura franco-arenosa, $\mathrm{pH} 5.5$ y $3.1 \%$ de materia orgánica, proveniente del sitio de recolección de las plantas y previamente desinfectado con bromuro de metilo. Después se combinaron con él $100 \mathrm{~g}$ de inóculo de una de dos cepas de hongos micorrícicos vesículo arbusculares (MVA), para establecer los dos siguientes tratamientos: (1) Glomus fasciculatum (Gf) y (2) Glomus intraradices (Gi), además del control (T), consistente en plantas con suelo sin inocular. En seguida, se trasplantó un hijuelo de agave por recipiente. Posteriormente se agregó otra porción de suelo y se les regó con 21 de agua cada tercer día durante los primeros tres meses (febrero a mayo de 1999) hasta el comienzo del periodo de lluvias en junio. Para evaluar los tratamientos se utilizó un diseño experimental completamente al azar, con seis repeticiones.

En cada uno de ellos se realizaron las siguientes determinaciones:

1. Fotosíntesis estacional. Las tasas instantáneas de asimilación de $\mathrm{CO}_{2}$ se registraron cada $2 \mathrm{~h}$ en periodos de $24 \mathrm{~h}$ con un sistema portátil de medición de intercambio de gases (LI-COR LI-6200), en seis hojas de diferentes plantas, en las fechas siguientes: 15-16 septiembre, 12-13 noviembre de 1999, 14-15 enero, 17-18 marzo, 30-31 mayo, 19-20 julio, 1-2 septiembre y 29-30 noviembre de 2000. La cámara original para registrar el intercambio de gases de 0.251 fue modificada para poder realizar la medición en hojas suculentas (Raveh et al., 1998; Pimienta-Barrios et al., 2001).

Los valores de asimilación neta diaria de $\mathrm{CO}_{2}$ se obtuvieron mediante la estimación con integrales del área de valores positivos de incorporación (tasas instantáneas $>0$ ) y los de asimilación negativa (tasas instantáneas $<0$ ). A los valores de ganancia positiva se les restaron los negativos para obtener los totales para un periodo de $24 \mathrm{~h}$.

2. Colonización por hongos MVA. Para evaluar esta variable, se recolectaron raíces formadas al inicio de las lluvias, conocidas como "raíces de lluvia" (Nobel, 1988), las cuales fueron fijadas en FAA (formaldehído:ácido acético: etanol 10:5:85) 
y aclaradas en una solución de $\mathrm{KOH}(10 \%)$, para su ablandamiento en una autoclave por 10 min a 10 libras. Esta solución se decantó y las raíces se lavaron para agregarles $\mathrm{HCl}(3 \%)$. Por último, se tiñeron con azul de tripano $(0.05 \%)$ en lactoglicerol (Phillips y Hayman, 1970). El porcentaje de colonización micorrícica se evaluó en 10 segmentos de raíz de $1 \mathrm{~cm}$, aplicando el método descrito por McGonigle et al. (1990) y con ayuda de un microscopio Zeiss.

3. Características anatómicas. Se hicieron cortes transversales con la ayuda de una navaja de rasurar y éstos se tiñeron con azul de toluidina $(0.5 \%)$. Se midió el espesor del clorénquima y parénquima medular.

4. Crecimiento vegetativo. De septiembre de 1999 a noviembre de 2000 se midió cada mes el crecimiento vegetativo, mediante el registro del número de hojas que se formaron en el ápice de la planta ("cogollo") y la medición de la longitud, el ancho y el espesor de las mismas.

\section{RESULTADOS Y DISCUSIÓN}

En 1999 los promedios mensuales diarios de las temperaturas mínimas durante el periodo en estudio oscilaron entre 4 y $15{ }^{\circ} \mathrm{C}$ durante la noche, y las máximas entre 25 y $29^{\circ} \mathrm{C}$ durante el día, mientras que en el año 2000 variaron de 5 a $17^{\circ} \mathrm{C}$ en la noche y 26 a $34^{\circ} \mathrm{C}$ en el día. Estos datos difieren de manera notable de los promedios mensuales registrados de 1990 a 1998, ya que en esos años la temperatura mínima osciló de 9 a $19{ }^{\circ} \mathrm{C}$ durante la noche y de 27 a $36{ }^{\circ} \mathrm{C}$ durante el día (Anónimo, 2006). Los meses más cálidos fueron abril y mayo en 2000 . Las noches más frías se presentaron en noviembre y diciembre de 1999, y en enero y febrero de 2000 (Fig. 1). El inicio del periodo de lluvias varió entre los años, ya que en algunos (1991, 1993 y 1998) comenzó en junio. En 2000, las primeras precipitaciones se presentaron en mayo y se incrementaron durante el verano; en 1999 y 2000 la temporada de lluvias terminó en octubre. La precipitación pluvial total en 2000 fue de 1009 mm (Fig. 1). Este valor fue mayor que el que se presentó en $1993(820 \mathrm{~mm})$ y cercano al de 1997 (1146 mm) (Anónimo, 2006).

En el Cuadro 1 se muestran los porcentajes de colonización en las raíces finas de Agave tequilana inoculadas con las cepas Gf y Gi de julio a octubre de 1999. Los números indican la ausencia de esta acción en $\mathrm{T}$ y su incremento de julio a septiembre, llegando a un valor de $47 \%$ para Gf y de 57\% para Gi. Su disminución en octubre se atribuye al hecho de que al final del verano las raíces inician su senescencia y es el momento en que termina la actividad de la simbiosis micorrícica (Nobel, 1988). 


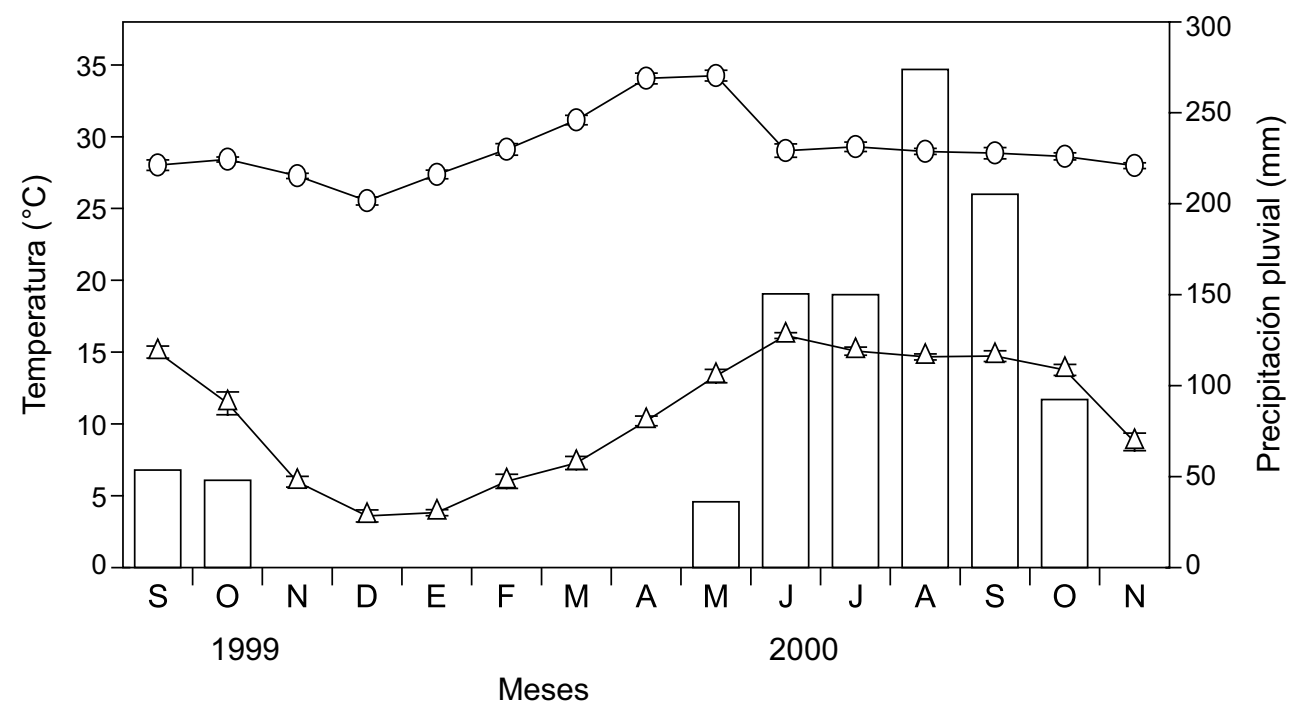

Fig. 1. Temperatura mínima $(\Delta)$ y máxima $(\mathrm{O})$ en promedio mensual, precipitación pluvial (barras) registradas en la localidad de Las Agujas municipio de Zapopan, Jalisco de septiembre de 1999 a noviembre de 2000. Promedios \pm ee $(n=30)$.

Cuadro 1. Porcentaje de colonización de raíces finas por hongos MVA en Agave tequilana durante el periodo de julio a octubre de 1999.

\begin{tabular}{lllll}
\hline \multirow{2}{*}{ Tratamiento } & \multicolumn{4}{c}{ Colonización (\%) } \\
\cline { 2 - 5 } & Jul & Ago & Sep & Oct \\
\hline G. fasciculatum & $61 \mathrm{a}$ & $65 \mathrm{a}$ & $90 \mathrm{a}$ & $70 \mathrm{a}$ \\
G. intraradices & $59 \mathrm{a}$ & $63 \mathrm{a}$ & $93 \mathrm{a}$ & $72 \mathrm{a}$ \\
Testigo & 0 & 0 & 0 & 0 \\
\hline
\end{tabular}

Los valores de colonización por hongos micorrícicos observados en A. tequilana fueron superiores a los reportados para Agave deserti por Cui y Nobel (1992), especie en la que alcanzaron un máximo de $64 \%$; dichos autores relacionaron este valor con un incremento de $19 \%$ en la asimilación de $\mathrm{CO}_{2}$ y atribuyeron tal respuesta a que la simbiosis micorrícica mejora la absorción de agua y nutrimentos. 
Por otro lado, en Opuntia robusta la supresión de la colonización de las raíces por hongos MVA con la aplicación del fungicida benlate en su rizósfera causó una reducción de $30 \%$ en la fotosíntesis en comparación con las plantas sin el mencionado tratamiento. Sin embargo, no hubo diferencias en la absorción de fósforo y agua entre las plantas a las que se aplicó benlate y a las que esto no se hizo (Pimienta-Barrios et al., 2003). En contraste, en Opuntia robusta la supresión de la colonización de hongos MVA por el fungicida redujo la fotosíntesis en 30\% (Pimienta-Barrios et al., 2003), pero esta disminución no se imputó a que la simbiosis micorrícica mejoró la absorción de agua y nutrimentos, como fue observado en Agave deserti.

Durante 1999, el valor máximo de asimilación neta diaria de $\mathrm{CO}_{2}$ se detectó en septiembre con Gi (321 mmol m $\left.\mathrm{m}^{-2} \mathrm{~d}^{-1}\right)$, seguido de Gf $\left(257 \mathrm{mmol} \mathrm{m}^{-2} \mathrm{~d}^{-1}\right)$, mientras que el menor se registró en $\mathrm{T}\left(222 \mathrm{mmol} \mathrm{m}^{-2} \mathrm{~d}^{-1}\right)$. En cambio, se redujo de manera significativa en noviembre, en particular en los individuos inoculados con Gf y en $\mathrm{T}$, en los que se observaron valores negativos $\left(-35.0 \mathrm{mmol} \mathrm{m}^{-2} \mathrm{~d}^{-1} \mathrm{y}-120 \mathrm{mmol} \mathrm{m}^{-2}\right.$ $\mathrm{d}^{-1}$ respectivamente), mientras que en el tratamiento Gi se presentó una asimilación positiva relativamente baja $\left(28 \mathrm{mmol} \mathrm{m}^{-2} \mathrm{~d}^{-1}\right)$ (Fig. 2). Dicha disminución se debe a que en este mes se registraron tasas fotosintéticas negativas durante el día, que se prolongaron durante las primeras horas de la noche (Figs. 3, 4, y 5). En Gf y T las tasas de asimilación positiva después de la medianoche fueron iguales o inferiores a $1.0 \mu \mathrm{mol} \mathrm{m} \mathrm{m}^{-2} \mathrm{~s}^{-1}$ (Figs. 3 y 5); en contraste, en Gi fueron más altas y oscilaron entre 1.0 y $7 \mu \mathrm{mol} \mathrm{m} \mathrm{m}^{-2} \mathrm{~s}^{-1}$ (Fig. 4). Esta reducción fue causada por una baja brusca en la temperatura $\left(4^{\circ} \mathrm{C}\right)$ cuando todavía el ambiente estaba todavía cálido y sugiere que las plantas de $A$. tequilana no tuvieron oportunidad de aclimatarse a tal descenso; además, indica que esta planta presenta menor resistencia a las temperaturas bajas, en comparación con otras especies de agave (Nobel et al., 1998).

En estudios con Agave americana y Agave tequilana (Raveh et al., 1998; Pimienta-Barrios et al., 2001) se ha encontrado que la mayor parte de la asimilación de $\mathrm{CO}_{2}$ se presenta durante la noche, cuando las temperaturas son frescas y la humedad relativa es alta. Estas condiciones reducen la pérdida de agua por transpiración (Nobel, 1994). Sin embargo, los datos sobre la asimilación de $\mathrm{CO}_{2}$ en plantas de $A$. tequilana inoculadas con Gi y Gf, y en T, durante 24 h en la mayoría de los meses evaluados (Figs. 3, 4 y 5) mostraron que además de la absorción nocturna (ruta fotosintética CAM), también se capta $\mathrm{CO}_{2}$ durante el día (al final de la tarde o al amanecer) a través de la ruta fotosintética $\mathrm{C}_{3}$.

La comparación del grosor del tejido fotosintético (clorénquima) con los promedios de asimilación neta diaria de $\mathrm{CO}_{2}$ registrados entre septiembre de 1999 y noviembre de 2000 mostró un incremento del primero en las plantas inoculadas con 


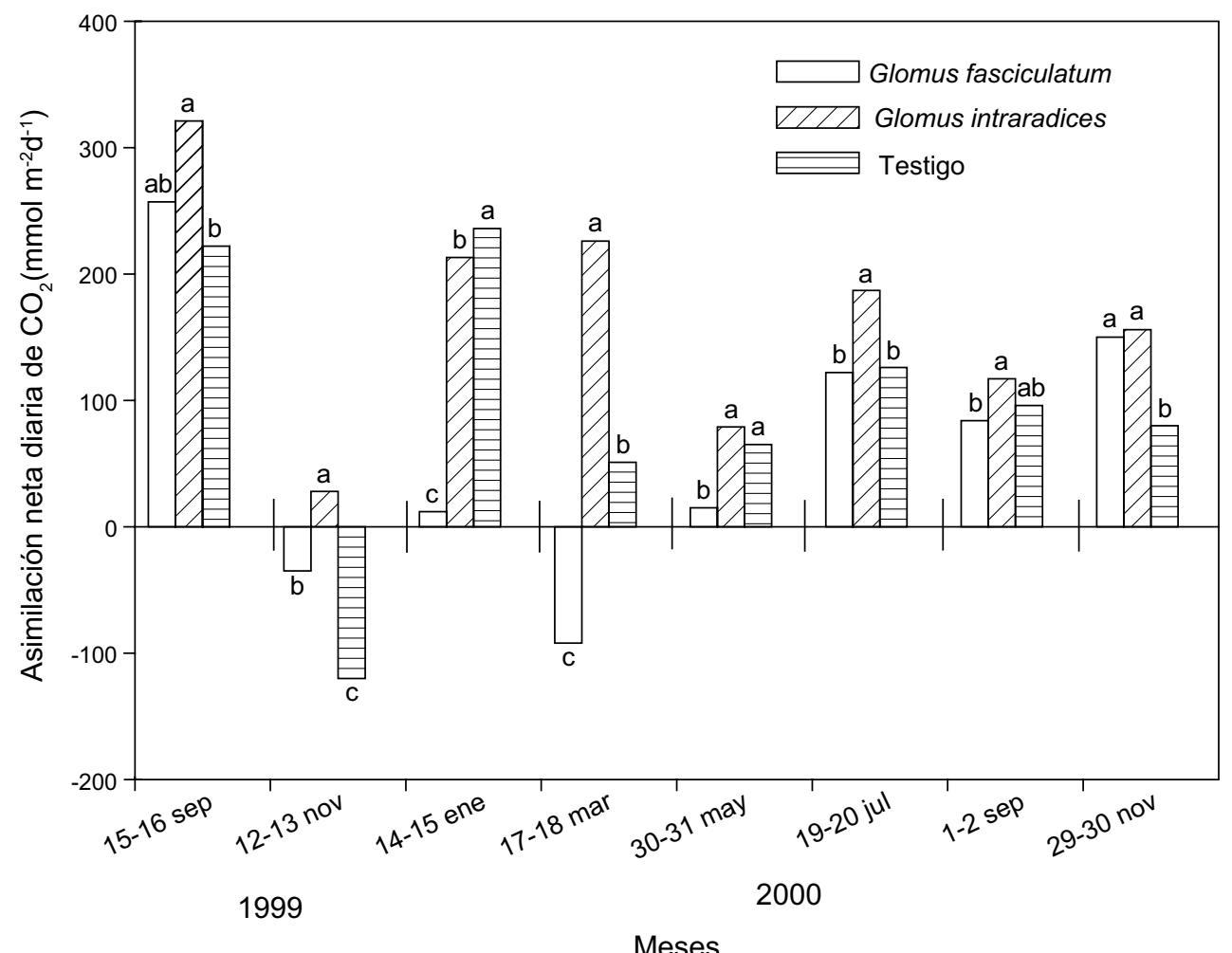

Fig. 2. Valores promedio diarios de asimilación neta diaria de $\mathrm{CO}_{2}$ en Agave tequilana registrados de septiembre de 1999 a noviembre de 2000. Barras con diferentes letras son significativamente diferentes según la prueba de Diferencia Mínima Significativa (DMS) (p $\leq 0.05), \mathrm{n}=6$.

Gf y Gi. Este resultado se relacionó con una mayor asimilación diaria de $\mathrm{CO}_{2}$, que alcanzó valores de $77 \%$ en plantas con Gi y de $2 \%$ con Gf (Cuadro 2) con respecto a T. No obstante que la simbiosis micorrícica incrementó la asimilación anual de carbono y el espesor del clorénquima y de las hojas, no tuvo un efecto positivo en las variables relacionadas con la morfología foliar, como el número, largo y ancho de las hojas (Cuadro 3).

Es probable que el aumento en el espesor esté relacionado con un fomento en la incorporación de nitrógeno, como se encontró en otras especies (Patton y Jones, 1989; Garnier et al., 1999; Slaton y Smith, 2002). Este elemento estimula el crecimiento en los órganos (i.e. las hojas) en desarrollo (MacAdam et al., 1989; Rademacher y Nel- 
Cuadro 2. Espesor de clorénquima y promedio de asimilación neta de $\mathrm{CO}_{2}$ de septiembre de 1999 a noviembre de 2000 en plantas jóvenes de $A$. tequilana, inoculadas con dos cepas de hongos micorrícicos.

\begin{tabular}{|c|c|c|}
\hline Tratamiento & Espesor del clorénquima (mm) & 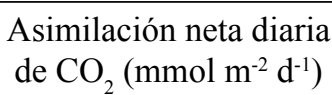 \\
\hline Glomus intraradices & $1.6 \mathrm{a}$ & $166 \mathrm{a}$ \\
\hline Glomus fasciculatum & $1.7 \mathrm{a}$ & $96 b$ \\
\hline Testigo & $0.9 b$ & $94 \mathrm{~b}$ \\
\hline
\end{tabular}

Valores promedio en una columna en particular seguidos con letras diferentes son estadísticamente diferentes $(\mathrm{p} \leq 0.05)$ por la prueba DMS.

Cuadro 3. Número, largo, ancho y espesor de las hojas en plantas jóvenes de Agave tequilana inoculadas con Glomus fasciculatum y G. intrardices durante el periodo de julio-agosto de 1999.

\begin{tabular}{lcccc}
\hline \multicolumn{1}{c}{ Tratamiento } & Número & Largo $(\mathrm{cm})$ & Ancho $(\mathrm{cm})$ & Espesor $(\mathrm{mm})$ \\
\hline G. fasciculatum & $16 \mathrm{a}$ & $46 \mathrm{~b}$ & $4.93 \mathrm{a}$ & $2.1 \mathrm{~b}$ \\
G. intraradices & $13 \mathrm{a}$ & $52 \mathrm{a}$ & $4.54 \mathrm{a}$ & $2.6 \mathrm{a}$ \\
Testigo & $12 \mathrm{a}$ & $54 \mathrm{a}$ & $4.89 \mathrm{a}$ & $2.3 \mathrm{~b}$ \\
\hline
\end{tabular}

Valores promedio en una columna en particular seguidos con letras diferentes son estadísticamente diferentes $(\mathrm{p} \leq 0.05)$ por la prueba DMS.

son, 2001). El aumento en el espesor foliar en A. tequilana se puede atribuir a que la simbiosis micorrícica mejora de forma notable la absorción de los minerales del suelo (Smith y Read, 1997; Clark y Zeto, 2000). Sin embargo, el ensanchamiento también podría deberse a un efecto hormonal, ya que la simbiosis micorrícica estimula la actividad metabólica radical y probablemente aumente la síntesis de citocininas en las raíces, donde se lleva a cabo este proceso (Salisbury y Ross, 1992; Srivastava, 2002). Las mencionadas fitohormonas activan la división celular y por consecuencia el crecimiento de diferentes órganos de la planta (Walch-Liu et al., 2000), como las hojas, donde además promueven la formación de cloroplastos e inducen la biosíntesis de clorofila (Srivastava, 2002). Lo anterior sugiere que los efectos estructurales y fisioló- 


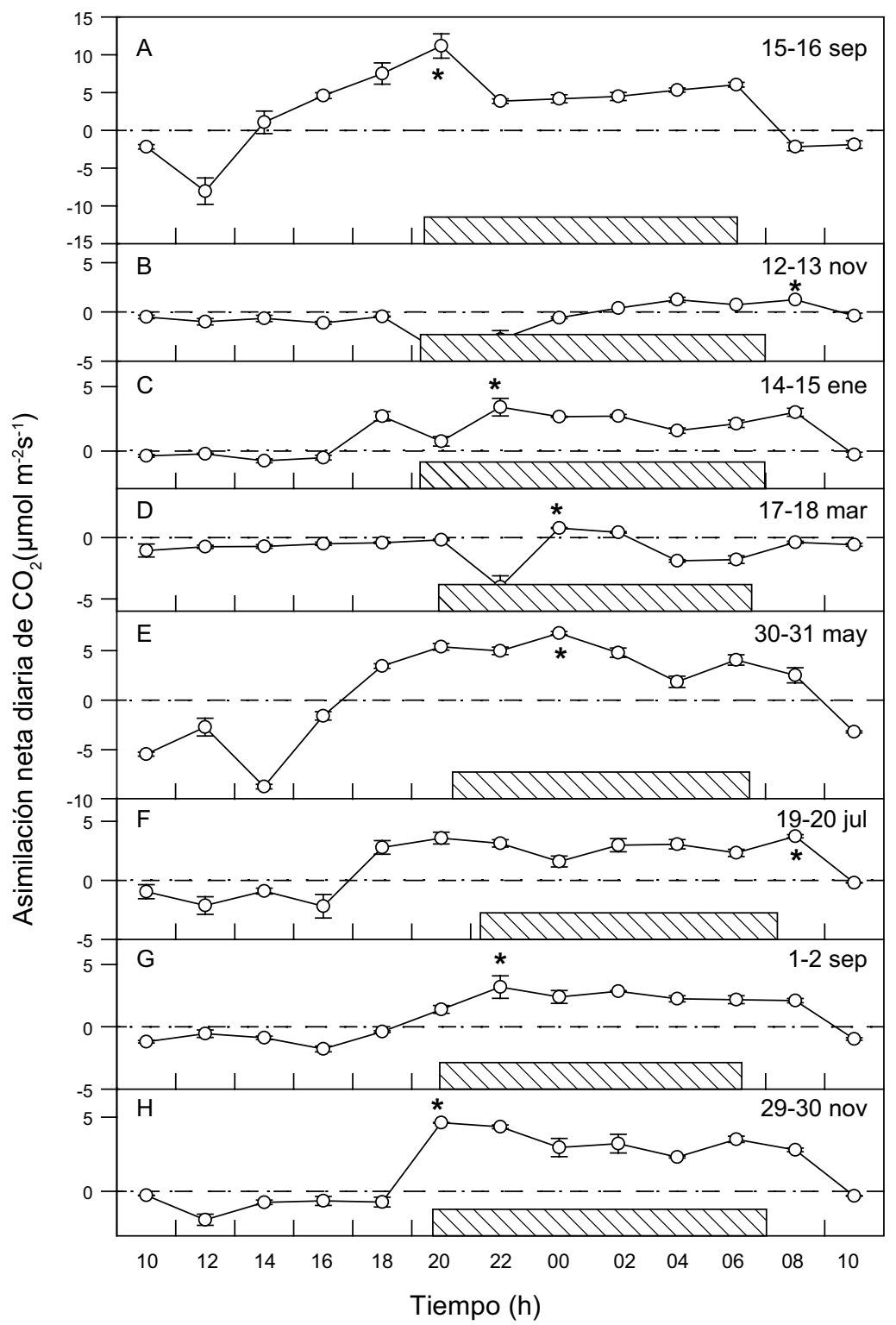

Fig. 3. Asimilación neta diaria de $\mathrm{CO}_{2}$ durante $24 \mathrm{~h}$ en plantas jóvenes de Agave tequilana inoculadas con el hongo micorrícico Glomus fasciculatum. Lecturas tomadas de septiembre de 1999 a noviembre de 2000. Los datos son promedios \pm ee $(n=6)$. La barra con líneas oblicuas corresponde al periodo nocturno y el asterisco $(*)$ señala la tasa máxima de asimilación instantánea. 
Pimienta-Barrios et al.: Efecto de las micorrizas arbusculares en plantas jóvenes de Agave tequilana

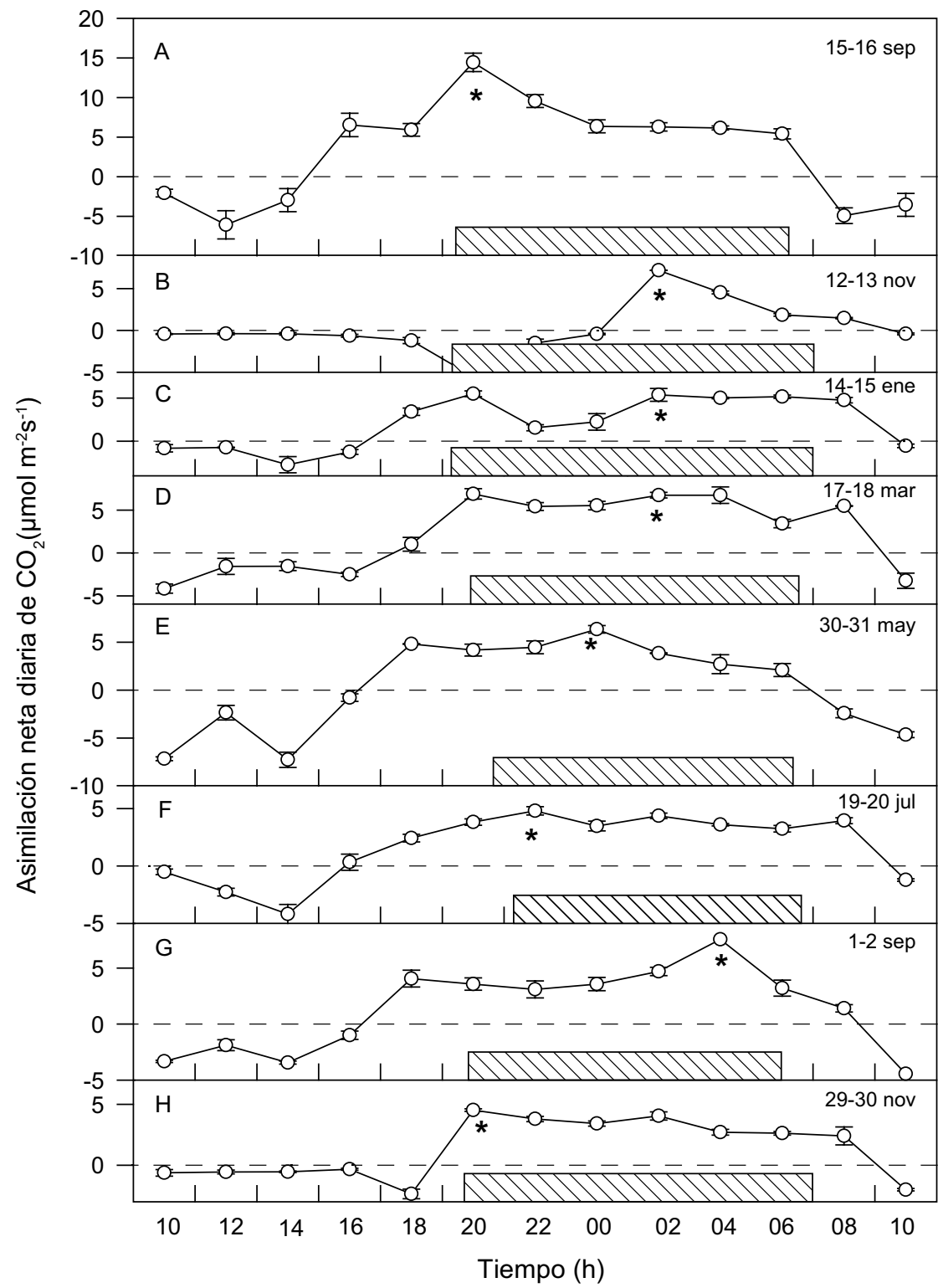

Fig. 4. Asimilación neta diaria de $\mathrm{CO}_{2}$ durante $24 \mathrm{~h}$ en plantas jóvenes de Agave tequilana inoculadas con el hongo micorrícico Glomus intraradices. Lecturas tomadas de septiembre de 1999 a noviembre de 2000. Los datos son promedios \pm ee $(n=6)$. La barra con líneas oblicuas corresponde al periodo nocturno. El asterisco $\left(^{*}\right)$ señala la tasa máxima de asimilación instantánea. 


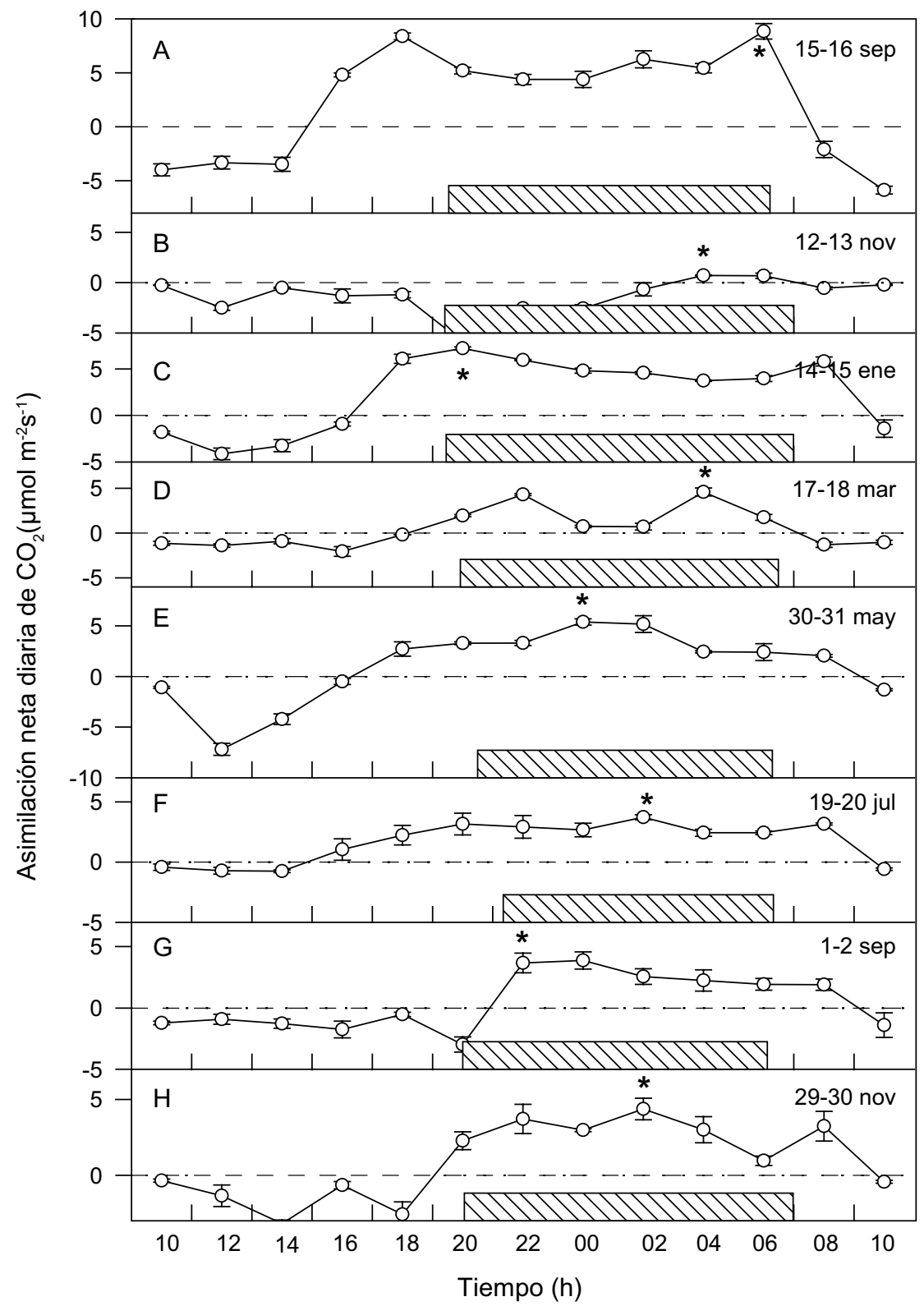

Fig. 5. Asimilación neta diaria de $\mathrm{CO}_{2}$ durante 24 h en plantas jóvenes de Agave tequilana sin inocular (testigo). Lecturas tomadas de septiembre de 1999 a noviembre de 2000. Los datos son promedios \pm ee $(n=6)$. La barra con líneas oblicuas corresponde al periodo nocturno. El asterisco $(*)$ señala la tasa máxima de asimilación instantánea. 
gicos observados en las hojas de $A$. tequilana en respuesta a la colonización por MVA no se pueden atribuir sólo a la absorción de agua y minerales (Hart y Trevors, 2005). Estas observaciones indican que la planta en cuestión presenta cierta dependencia fisiológica de las micorrizas, como ocurre en otras especies vegetales, principalmente en sus primeras etapas de desarrollo (Salisbury y Ross, 1992; Lambers et al., 1998).

Estudios recientes muestran que la agricultura se desarrolló en el siglo XX sin enfocarse en el manejo de los microorganismos de la rizósfera, no obstante que su actividad suele desempeñar un papel elemental en el aprovechamiento agrícola sustentable (Vandermeer, 1995; Hart y Trevors, 2005), pues estos constituyentes del suelo son importantes para las funciones básicas como la descomposición de materiales orgánicos, la adquisición y la fijación de nitrógeno y fósforo, que son parte esencial de las redes tróficas. Investigaciones recientes revelaron que tales componentes mejoran las relaciones hídricas de las plantas al influir en las conductancias estomática e hidráulica (Auge, 2001), además de que promueven el establecimiento de plántulas, la resistencia a patógenos, la tolerancia a herbívoros y a metales pesados, y que mejoran la estructura de los suelos (Hart y Trevors, 2005).

En los últimos 50 años se han utilizado métodos de manejo que incrementan el rendimiento agrícola o reducen el tiempo hasta la cosecha, con apoyo de fertilizantes, herbicidas y plaguicidas. Estas prácticas han erradicado a la mayoría de los microbios de la rizósfera en los principales agroecosistemas (Matson et al., 1997), lo que en consecuencia puede obstaculizar la introducción o recuperación de poblaciones benéficas de microorganismos en los suelos así afectados.

Éste es el caso del cultivo del agave a partir de la última década, a causa de la creciente demanda nacional e internacional del tequila. Si bien debe reconocerse que con ello se tiene un mayor éxito en la producción, el empleo intensivo de agroquímicos acompañado de métodos de manejo del suelo orientados al control de malezas puede disminuir con el tiempo las poblaciones de estos microbios asociados a la rizósfera de las plantaciones de A. tequilana. Este hecho puede afectar las propiedades físicas y químicas, así como las cadenas o redes tróficas del suelo, y a la larga su fertilidad natural y su salud, a causa de la alteración de los ciclos de algunos de los principales minerales (Bethlenfalvay y Linderman, 1992; Smith y Read, 1997).

\section{CONCLUSIONES}

La inoculación de plantas jóvenes de Agave tequilana con hongos micorrícicos aumentó la asimilación neta diaria de $\mathrm{CO}_{2}$, siendo ésta mayor en la cepa $\mathrm{Gi}$ 
en comparación con Gf. Ambas fueron superiores a los valores de ganancia de carbono observados sin hongos MVA. El incremento de la fotosíntesis se asoció con cambios en la estructura foliar, ya que en los individuos tratados de esta manera las hojas tuvieron mayor espesor, sobre todo en el clorénquima. Por el contrario, no se detectaron diferencias en el crecimiento entre plantas inoculadas y las que no lo fueron.

\section{AGRADECIMIENTOS}

Se agradece a Tequila Herradura por el financiamiento de la investigación; un reconocimiento especial al Dr. Servando Carvajal Hernández y a la Dra. Blanca C. Ramírez Hernández por su valiosa colaboración en la revisión y edición del manuscrito así como al comité editorial de la revista y a los revisores por sus aportaciones al escrito.

\section{LITERATURA CITADA}

Anónimo. 2006. Registro histórico de 1990 hasta 2006. Comisión Nacional del Agua. México, D.F.

Auge, R. M. 2001. Water relations, drought and vesicular-arbuscular mycorrhizal symbiosis. Mycorrhiza 11(1): 3-42.

Bethlenfalvay, G. J. y R. G. Linderman (Eds.). 1992. Mycorrhizae in sustainable agriculture. Am. Soc. Agron. ASA Special publication No. 54. Madison, WI. 124 pp.

Clark, R. B. y S. K. Zeto. 2000. Mineral acquisition by arbuscular mycorrhizal plants J. Plant Nut. 23(7): 867-902.

Cui, M. y P. S. Nobel. 1992. Nutrient status, water uptake and gas exchange for three desert succulents infected with mycorrhizal fungi. New Phytol. 122(4): 643-649.

Ferrera-Cerrato, R. y C. González-Chávez. 1998. La simbiosis micorrízica en el manejo del vivero de los cítricos. In: Ferrera-Cerrato, R. y J. Pérez-Moreno (eds.). Manejo de agroecosistemas sostenibles. Textos Universitarios. Universidad Autónoma de Tlaxcala. Tlaxcala. pp. 37-64.

García, E. 1981. Modificaciones al sistema de clasificación climática de Köppen (para adaptarlo a las condiciones de la República Mexicana). Instituto de Geografía, Universidad Nacional Autónoma de México. México, D.F. 252 pp.

Garnier, E., J. L. Salager, G. Laurent y L. Sonié. 1999. Relationships between photosynthesis, nitrogen and leaf structure in 14 grass species and their dependence on the basis of expression. New Phytol. 143(1): 119-129. 
Hart, M. y J. T. Trevors. 2005. Microbe management: application of mycorrhyzal fungi in a sustainable agriculture. Frontiers in Ecology and the Environment 10(3): 533-539.

Kyde, M. M y A. B. Gould. 2000. Mycorrhizal endosymbiosis. In: Bacon, C. W. y J. F. White (eds.). Microbial endophytes liver. Marcel Dekker Blackwell. Londres. pp. 161-198.

Lambers, H., F. S. Chapin III y T. L. Pons. 1998. Plant physiological ecology. SpringerVerlag. Nueva York. 540 pp.

MacAdam, J. W., J. J. Volenec y C. J. Nelson. 1989. Effects of nitrogen on mesophyll cell division and epidermal cell elongation in tall fescue leaf blades. Plant Physiol. 89(2): 549-556.

Matson, A. P. A., W. J. Parton, A. G. Power y M. J. Swift. 1997. Agricultural intensification and ecosystem properties. Science 277(5325): 504-509.

McGonigle, T. P., M. H. Miller, D. G. Evans, G. L. Fairchild y J. A. Swan. 1990. A new method which gives an objective measure of colonization of roots by vesiculararbuscular mycorrhizal fungi. New Phytol. 115(3): 495-501.

Morton, J. B. 2000. Evolution of endophytism in arbuscular mycorrhizal fungi of Glomales. In: Bacon, W. C. y F. J. White (eds.). Microbial endophytes. Marcel Dekker Balckwell, Inc. Nueva York. pp. 121-140.

Morton, J. B. y G. L. Benny. 1990. Revised classification of arbuscular mycorrhizal fungi (Zigomycetes): a new order, Glomales, two new suborders, Glomineae and Gigasporinae, and two new families, Acaulosporeceae and Gigasporaceae, with an amendation of Glomaceae. Mycotaxon 37(1): 471-491.

Nobel, P. S. 1988. Environmental biology of agaves and cacti. Cambridge University Press. Cambridge. 270 pp.

Nobel, P. S. 1994. Remarkable agaves and cacti. Oxford University Press. Nueva York. 180 pp.

Nobel, P. S., G. Castañeda, G. North, E. Pimienta-Barrios y J. A. Ruiz-Corral. 1998. Temperatures influences on leaf $\mathrm{CO}_{2}$ exchanges, cell viability and cultivation range for Agave tequilana. J. Arid Environ. 39(1): 1-19.

Orcutt, M. D. y E. T. Nilsen. 2000. The physiology of plants under stress: soil and biotic factors. John Wiley \& Sons. Nueva York. 684 pp.

Patton, L. y M. B. Jones. 1989. Some relationships between leaf anatomy and photosynthetic characteristics of willows. New Phytol. 111(4): 657-661.

Phillips, J. M. y D. S. Hayman. 1970. Improved procedures for clearing roots and staining parasitic and vesicular-arbuscular mycorrhizal fungi for rapid assessment of infection. Trans. Br. Mycol. Soc. 55: 158-161.

Pimienta-Barrios E., C. Robles-Murguía y P. S. Nobel. 2001. Net $\mathrm{CO}_{2}$ uptake for Agave tequilana in a warm and a temperate environment. Biotropica 33(2): 312-318.

Pimienta-Barrios, E., A. Muñoz-Urias, M. E. González del Castillo-Aranda y P. S. Nobel. 2003. Effects of benomyl and drought on the mycorrhizal development and daily net $\mathrm{CO}_{2}$ uptake of a wild platyopuntia in a rocky semiarid environment. Ann. Bot. 92(2): $1-7$.

Rademacher, I. F. y J. C. Nelson. 2001. Nitrogen effects on leaf anatomy within the intercalary meristems of tall fescue leaf blades. Ann Bot. 88(5): 893-903. 
Raveh, E., N. Wang y P. S. Nobel. 1998. Gas exchange and metabolite fluctuations in green and yellow bands of variegated leaves of monocotyledonous CAM species Agave americana. Physiologia Plantarum 103(1): 99-106.

Ruiz-Lozano, J. M. y R. Azcón. 1995. Hyphal contribution to water uptake in mycorrhizal plants as affected by the fungal species and water status. Physiologia Plantarum 95(3): 472-478.

Safir, G. R. 1990. Micorrizas arbúsculo-vesicular y la productividad agrícola. In: Carlson, P. S. (ed.). Biología de la productividad de cultivos. AGT Editor, S.A. México, D.F. pp. 201-222.

Salisbury, F. B. y C. W. Ross. 1992. Plant physiology. 4a. ed. Wadsworth, Belmont. 422 pp.

Slaton, M. y W. K. Smith. 2002. Mesophyll architecture and cell exposure to intercellular air space in alpine, desert, and forest species. Int. J. Plant Sci. 163(6): 937-948.

Smith, S. E. y D. J. Read. 1997. Mycorrhizal symbiosis. 2a. ed. Academic Press. San Diego. $605 \mathrm{pp}$.

Srivastava, M. L. 2002. Plant, growth and development: hormones and environment. Academic Press. San Diego. 772 pp.

Trappe, J. M. 2005. A. B. Frank and mycorrhizae: the challenge to evolutionary and ecologic theory. Mycorrhiza 15(4): 277-281.

Vandermeer, J. 1995. The ecological basis of alternative agriculture. Ann. Rev. Ecol. Syst. 26: 201-224.

Walch-Liu, P., G. Neumann, F. Bangerth y C. Engels. 2000. Rapid effects of nitrogen form on leaf morphogenesis in tobacco. J. Exp. Bot. 51(343): 227-237.

Wang, B. y Y. L. Quiu. 2006. Phylogenetic distribution and evolution of mycorrhizas in land plants. Mycorrhiza 16(15): 299-379. 